not very well, and he forthwith gave her an order. In the second case, the woman had gone from home two days previous to my visit (her daughter informed $\mathrm{me}$ ) to help her sister to kill and salt a pig, and would not return until the end of the week. Thus you will observe, by the double journey I travelled a distance of thirty-six miles for no purpose. If, by your perseverance, you can do anything for us in the forthcoming session of Parliament, the profession will have great reason to rejoice. If need be, I shall not object to a further donation. I may mention that my salary is $£ 30$ per annum for a very large district.-I am, \&c."

\section{ON THE NUTRITIVE VALUE OF "EXTRACTUM CARNIS."}

To the Editor of The LanceT.

SIR,-Your impression of Nov. 11th (p. 547) contained a communication from Baron Liebig on the nutritive value of the "Extractum Carnis," in which he says: "I should be glad if these lines could assist in clearing up public opinion on the extract of meat as a nutriment: my aim being, on the one hand, to reduce to their right limit hopes too sanguine; on the other, to point out the true share which the extract of meat can have in the nutrition of the people of Europe."

Both the public and the profession are much indebted to you, Sir, for the prominence you have given to this subject in the pages of THE LANCET. The matter has been most ably discussed by men of the highest scientific attainments; and the result has been to establish the fact that the Extractum Carnis is not deserving the high reputation with which it was introduced to the public.

The article is now sold at the price of twenty shillings per pound, and, in the debility attendant upon sickness, is eagerly sought for, and the price cheerfully, though, alas! too often most inconveniently, paid.

In the same letter to which $I$ have referred, the Baron states simply "that the extract is identical with beef-tea, minus albumen," \&c.; and no longer claims the high nutritive character which he assigned to it in a former communication, and from which I extract the following:-That " one pound contains the soluble matter of thirty pounds of flesh, free from all fat; and if boiled with a few slices of bread, potatoes, and a little salt, is sufficient to make broth for $128 \mathrm{men}$ in the field, and of a strength which is not to be obtained in the best hotels." That is, one drachm of the extract to each man.

Under these circumstances, and encouraged by the expressed desire of the Baron to guide the public in coming to a right conclusion, I would take the liberty of asking-as a member of the medical profession greatly interested in the subject, and on behalf of the less informed public who purchase this article, depending on the great nutritive properties assigned to itwhether Baron Liebig still adheres to the statement contained in the above extract?

Malden, Nov. 1865.

I am, Sir, your obedient servant,

E. CHILD, M.R.C.S.

To the Editor of The LANCET.

SIR, - I am really sorry to have to trouble you again on the subject of Liebig's Extract ; but since Messrs. Allen and Hanburys choose to assume that a statement made by me in my previous letter requires correction, I must crave your permission to set myself right in the matter.

Messrs. Allen and Hanburys quote the Bavarian Pharmacopœia, which may be a very good book, but is certainly not accessible to the English reader, and in which five drachms of the Extract are directed to be used with each pint of water; and they state, "These are the directions which we believe are generally adopted." In this assertion they are altogether wrong. I have now before me three labels taken from pots of the Extract sold by different dealers. On one the directions given are--"a small teaspoonful is to be mixed with a breakfast-cupful of hot water " on the second, "one-third of a teaspoonful to a cup of boiling water "' and on the third, "dissolve a teaspoonful of the Extract in a pint of boiling water." Now, Liebig's Extract contains on an average about one-fifth part of water, and, therefore, a deduction of one-fifth must be made from the above quantities in order to arrive at the solid matter therein contained.

Surely it behoved Messrs. Allen and Hanburys to ascertain the nature of the directions sold with Liebig's Extract in this

country before searching over the Bavarian Pharmacopoia, and troubling you with their last communication, attributing error to Your obedient servant,
Brewer-street, Nov. 28th, 1865. Analytical Chemist.

Thomas Vosper,

\section{HEREDITARY SYPHILIS \\ To the Editor of The Laxcer.}

Sir,-In the paper by Mr. Dunn, jun., read at the last meeting of the Medical and Chirurgical Society, on the Treatment of Hereditary Syphilis, and in the discussion to which it gave rise, no mention was made of one remarkable feature of this virulent animal poison-namely, its tendency, like smallpox and other eruptive diseases, to escape by the surface. This is manifested by the various forms of cutaneous eruptions, by the fissures at the angles of the mouth, by the condylomata surrounding the anus, and by the snuffles.

In the case of this and probably of every other form of syphilis, the vapour bath, by promoting this tendency, is an agent of great value in assisting to expel the disease per viam naturalem, in aid of other remedies, such as mercury and iodine, by directing them to the surface. In hot countries, where the non-mercurial mode of treating syphilis is most in vogue, great faith is reposed in sarsaparilla and guaiacum, whilst in this country they are considered almost inert. The difference is referable to the temperature; in hot climates they are powerful sudorifics, and hence their efficacy. This may be supplied by the vapour bath, and keeping the patient in a warm room. It has been observed that it is hardly possible to salivate a patient with mercury, or to iodize a patient with iodine, who is using the vapour bath whilst undergoing a course of treatment by these remedies. It was a saying of Abernethy " that he only knew of two cases in which patients had lost their noses by the venereal disease, but that he knew at least of two thousand from the abuse of mercury." Not one of these accidents probably would have happened if the vapour bath had been employed in aid of the mercurial treatment.

Nov. 1865. I am, Sir, yours \&c.,

$$
\text { F. R. M. C. S. }
$$

\section{I T A L S T A T I S T I C S.}

To the Editor of THe LANCET.

SrR, - Will you allow me to make a few remarks on two in. teresting statistical articles published in your number of the 4th of November?

With respect to one of these-that on the Vital Statistics of Iceland, which is written by a friend of mine,-I have only to note two clerical errors. The author's name should be "Hjaltelin," not "Hjatelin." And the parish which he mentions as so remarkably healthy is that of "Thingvalla": the resemblance of the Icelandic letters "Th" to the Roman " $P$ " has led to the mistake.

With respect to Dr. Chambers's article on the Climate of Italy, I wish to point out that, though the writer's statistics appear perfectly valid for his purpose-which is that of proving the relative infrequency of chronic diseases in Italy,--they might leave a superficial reader to underrate the absolute frequency of some of these diseases, and that to a considerable extent; for Dr. Chambers has calculated the mortality of each disease according to its proportion to the total mortality, therein following a plan legitimate enough under the special circumstances of the case, but differing from that usually employed by statisticians, who take for their basis of calculation the population, not the total mortality.

Proceeding on this latter plan, and taking Dr. Chambers's figures, I find that the annual mortality from phthisis is in London 287. per 100,000 of population; and in Genoa 265, or very little lower. From cancer, it is in London 47 per 100,000, and in Genoa 55 ; from epilepsy, 13 in London, and 14 in Genoa; from chronic diseases of the heart, 101 in London, and 105 in Genoa. In these three latter cases, then, Genoa stands a little worse than London, instead of considerably better. The better way of stating the facts would be to say, that while death by chronic disease is not quite so frequent in Genoa as in London, death by acute disease is enormously more so. Of course Dr. Chambers's comparison is left untouched by this alteration of mine; but the character of the climate of Italy is to a certain extent damaged thereby.

Clifton, Nov, 1865.

I am, Sir, your obedient servant, JoHN BEDdoe, M.D., F.S.S. 